\title{
ANALISA KEBISINGAN LALU LINTAS UDARA DI SEKITAR BANDAR UDARA DEO KOTA SORONG
}

\author{
Iwan Rachman $^{1}$, Hendrik Pristianto ${ }^{2}$ \\ ${ }^{1,2}$ Program Studi Teknik Sipil Universitas Muhammadiyah Sorong \\ Jalan Pendidikan No 27 Kota Sorong, Propinsi Papua Barat \\ Email : tekniksipilsorong@gmail.com
}

\begin{abstract}
ABSTRAK
Landasan Bandara DEO Kota Sorong sepanjang 2116 M, tepat berada tidak jauh dari bibir pantai, membuat lalu lintas bandara sedikitnya berdampak terhadap aktifitas warga. Dampak yang paling signifikan adalah timbulnya kebisingan dari pesawat yang datang dan pergi. Bandara DEO Sorong saat ini didarati oleh pesawat untuk penerbangan perintis dan domestik, dengan jumlah rata rata didarati 250 pesawat setiap bulannya, atau sehari rata-rata 6 - 8 buah dengan jenis pesawat umumnya tipe Boeing 737 dengan mesin turbo jet, juga didarati pesawat jenis Xian MA-60, Fokker-100, CN-235, CASA C 212, dan DHC-6. Penelitian ini bertujuan untuk mengetahui bagaimana tingkat kebisingan yang ditimbulkan oleh suara mesin pesawat terbang di sekitar Bandara Dominee Eduard Osok (DEO) Sorong. Metode penelitian ini menggunakan metode Observasi / penelitian lapangan, yaitu melakukan pengamatan secara langsung ke lokasi penelitian yang ada untuk mendapatkan data primer. Tingkat kebisingan di Bandara DEO Sorong terutama di lokasi pengukuran (A1) Sekitar landas pacu bagian barat (75,8dBA), dan (A3) Landas Pacu Bagian Timur (84,7 dBA) di atas ambang baku mutu (55 dBA). Dan (A2) Area terminal Penumpang (75,9 dBA) tingkat kebisingannya diatas ambang baku mutu ( $60 \mathrm{dBA})$.
\end{abstract}

Kata Kunci : kebisingan, lalu lintas, bandara, 


\section{PENDAHULUAN}

\section{Latar Belakang}

Bandar udara (Bandara) Dominee Eduard Osok (DEO) Kota Sorong, sejak dialihkan dari Bandara Jefman, Pulau Salawati, yang sekarang masuk wilayah omestic tive Kabupaten Raja Ampat, omest kontribusi tambahan bagiperkembangan kota Sorong. Arus lalu lintas kedatangan dan keberangkatan pesawat yang membawa penumpang keluar masuk kota Sorong menjadi omestic bahwa aktifitas bandara DEO semakin padat.

Dengan Luas wilayah $1.105 \mathrm{~km}^{2}$ yang didiami penduduk 190.341 jiwa, maka rata-rata tingkat kepadatan penduduk Kota Sorong adalah sebesar $91 \mathrm{jiwa} / \mathrm{km}^{2}$. Kecamatan yang paling tinggi tingkat kepadatannya adalah Distrik Sorong Manoi yakni sebesar 313 jiwa/ $\mathrm{km}^{2}$, sedangkan yang paling terendah Distrik Sorong Kepulauan yakni 49 jiwa $/ \mathrm{km}^{2}$.

Landasan Bandara sepanjang $2116 \mathrm{M}$, tepat berada tidak jauh dari bibir pantai, membuat lalu lintas bandara sedikitnya berdampak terhadap aktifitas warga. Dampak yang paling signifikan adalah timbulnya kebisingan dari pesawat yang omest dan pergi. Bandara DEO Sorong saat ini didarati oleh pesawat untuk penerbangan perintis dan omestic, dengan jumlah rata rata didarati 250 pesawat setiap bulannya, atau sehari rata-rata 6-8 buah dengan jenis pesawat umumnya tipe Boeing 737 dengan mesin turbo jet, juga didarati pesawat jenis Xian MA-60, Fokker-100, CN-235, CASA C 212, dan DHC-6.

\section{Tujuan Penelitian}

Penelitian ini bertujuan untuk mengetahui bagaimana tingkat kebisingan yang ditimbulkan oleh suara mesin pesawat terbang di sekitar Bandara Dominee Eduard Osok (DEO) Sorong.

\section{METODE}

\section{Lokasi dan Waktu Penelitian}

Lokasi dan waktu penelitian adalah sebagai berikut :

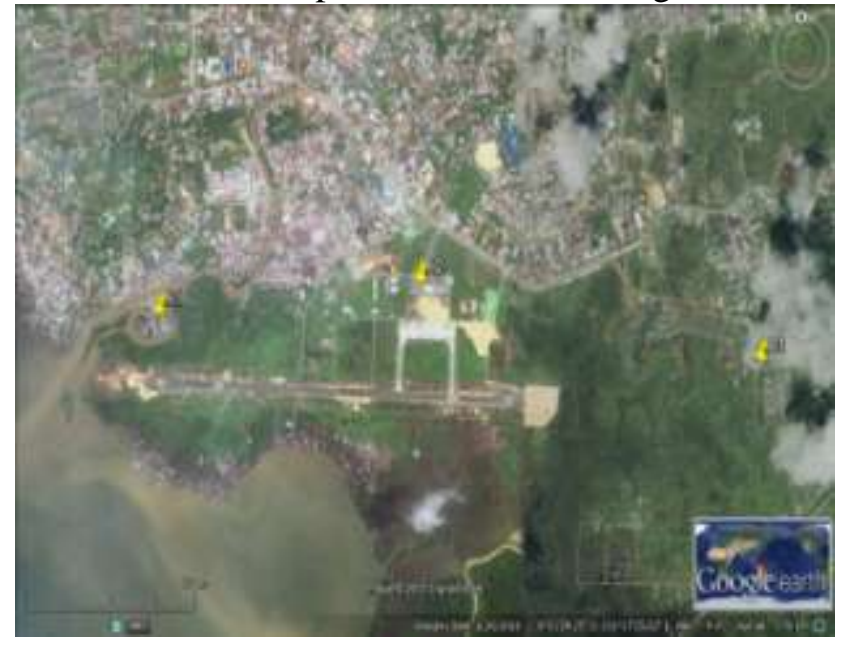

Gambar 1. Lokasi Studi

1. Lokasi penelitian adalah pada Kawasan Operasional Bandara Udara Dominee Eduard Osok Kota Sorong terletak pada $00^{\circ} 53^{\prime} 39^{\prime \prime} \mathrm{LU} 131^{\circ} 17^{\prime} 20^{\prime \prime} \mathrm{BT}$.

2. Jarak dari lokasi penelitian.

Jarak dari titik penelitian ke apron adalah:

A1. 1.408 Meter

A2. 1.63 Meter

A3. 1.774 Meter

Jarak dari lokasi penelitian.

Jarak dari titik penelitian ke runway adalah:

A1. 406 Meter

A2. 422 Meter

A3. 1.448 Meter

Jarak antara titik penelitian adalah:

A1 ke A2. $\pm 1,38 \mathrm{~km}$

A2 ke A3. $\pm 1,65 \mathrm{~km}$

A1 ke A3. $\pm 3 \mathrm{~km}$

3. Waktu penelitian dilakukan selama dua bulan yaitu dari bulan Agustus sampai Oktober 2013.

\section{Pemilihan Sampel}

a. Bandara Dominee Eduard Osok Sorong.

lokasi titik penelitian A2. $00^{\circ} 53^{\prime} 25.2^{\prime \prime} \mathrm{LU} 131^{\circ} 17^{\prime} 23.9^{\prime \prime} \mathrm{BT}$ 
b. Pemukiman sekitar Bandara Dominee Eduard Osok Sorong. lokasi titik penelitian A1. 00 $53^{\prime} 28.9^{\prime \prime} \mathrm{LU} 131^{\circ} 16^{\prime} 40.0^{\prime \prime} \mathrm{BT}$. lokasi titik penelitian A3. $00^{\circ} 53^{\prime} 32.0^{\prime \prime} \mathrm{LU} 131^{\circ} 18^{\prime} 16.1^{\prime \prime} \mathrm{BT}$.

\section{Jenis dan Sumber Data}

a. Data Primer, yaitu data yang didapatkan melalui hasil penelitian ke lapangan yaitu Bandara Dominee Eduard Osok Sorong. Dan pemukiman disekitar bandara.

b. Data Sekunder, yaitu data yang didapatkan melalui berbagai literature atau kepustakaan yang ada atau beberapa peraturan perundang-undangaan lainnya yang berhubungan dengan perhubungan dan kebandar udaraan.

\section{Teknik / Metode Pengumpulan Data}

1. Penelitian / study kepustakaan, yaitu dengan mempelajari buku-buku literatur, karangankarangan ilmiah yang berkaitan dengan kebisingan akibat lalu lintas penerbangan dan lain lain.

2. Metode Observasi / penelitian lapangan, yaitu melakukan pengamatan secara langsung ke lokasi penelitian yang ada untuk mendapatkan data primer.

\section{Metode Analisis Data.}

a. Deskriptif, yaitu dengan cara memaparkan secara jelas data yang telah diperoleh.

b. Komperatif, yaitu dengan cara membandingkan data yang diperoleh dari hasil penelitian dengan data-data yang di peroleh dari penelitian kepustakaan

Alat yang digunakan.

1. Sound level meter + statif

2. Alat tulis

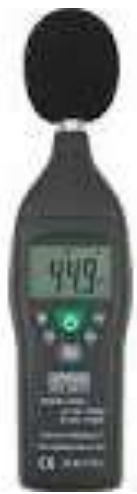

\section{HASIL DAN PEMBAHASAN}

Gambar 2. Sound Level

Data umum Bandara DEO Sorong :

Tabel 1. Data Runway

\begin{tabular}{ccc}
\hline & Panjang & Permukaan \\
\hline $\mathrm{m}$ & $\mathrm{ft}$ & \\
\hline 2116 & 6.446 & Aspal \\
\hline
\end{tabular}

Tabel 2. Jenis pesawat yang melalui bandara DEO Sorong

\begin{tabular}{ccc}
\hline \multirow{2}{*}{ MASKAPAI } & JENIS PESAWAT & TYPE \\
\hline Express Air & DORNIER & D-328 \\
\cline { 2 - 3 } & BOEING & B-737 300, 200 \\
\hline Merpati Airlines & BOEING & B-737 300 \\
\cline { 2 - 3 } & DHC & DHC-6 \\
\hline Sriwijaya Air & BOEING & B-737 300, 500 \\
\hline Travira Air & CARAVAN & B1900D \\
\hline Susi Air & CESSNA & C208B \\
\hline Deraya Air & SHORT & SD3-60 \\
\hline Pelita Air & FOKKER & F-100 \\
\hline Wings Air & ATR & ART72-500 \\
\hline Garuda Indonesia & Bombardier & CRG 100
\end{tabular}




\section{Hasil Penelitian}

1. Jarak dari lokasi penelitian.

a. Jarak dari titik penelitian ke apron adalah:

A1. 1.408 Meter

A2. 1.63 Meter

A3. 1.774 Meter

b. Jarak dari titik penelitian ke runway adalah:

A1. 406 Meter

A2. 422 Meter

A3. 1.448 Meter

Jarak antara titik penelitianadalah:

A1 ke A2. $\pm 1,38 \mathrm{~km}$

A2 ke A3. $\pm 1,65 \mathrm{~km}$

A1 ke A3. $\pm 3 \mathrm{~km}$

Lokasi titik penelitian A1.00 $53^{\prime} 28.9^{\prime \prime} \mathrm{LU} 131^{\circ} 16^{\prime} 40.0^{\prime \prime} \mathrm{BT}$.

Lokasi titik penelitian A2. $00^{\circ} 53^{\prime} 25.2^{\prime \prime} \mathrm{LU} 131^{\circ} 17^{\prime} 23.9^{\prime \prime} \mathrm{BT}$

Lokasi titik penelitian A3. 00 53'32.6"LU 131 ${ }^{\circ} 18^{\prime} 16.7^{\prime \prime} \mathrm{BT}$

2. Jenis Pesawat yang beroperasi di Bandara DEO Sorong

Jenis-jenis pesawat yang beroperasi di Bandara DEO Sorong dari jasa penerbangan di antaranya yaitu Merpati (Boeing 737 seri 300), dan (DHC-06), Wings (ATR 72/500), Expres (B-737/200/300/500), dan (Dornier 328), Sriwijaya (B-737/300/500), Garuda Indonesia Airways (Bombardier).

3. Waktu dan Hasil Pengukuran

Waktu dan hasil Pengukuran dilaksanakan di tiga lokasi di mulai dari tanggal $13 \mathrm{~s} / \mathrm{d} 26$

Desember 2013 Pada Lokasi A1, A2 dan A3 dilaksanakan pada jam 17.00 - 16.00 WIT.Dapat dilihat pada Tabel. 5

4. Contoh Perhitungan Nilai Leq

Contoh Perhitungan Pada Titik Pertama ( Ujung Run Way Bagian Barat )

Titik A jam 7.00 - 08.00, Sebagai Berikut:

Lmin $=75.7 \mathrm{dBA}$

Lmax $=80.5 \mathrm{dBA}$

Leg $=10 \log \left(0.5 \times 10^{75.7 / 10}+0.5 \times 10^{80.5 / 10}\right)$

$=10 \log \left(0.5 \times 10^{7.57}+0.5 \times 10^{8.05}\right)$

$=10 \log (74677684)$

$=10(7.873191)$

Leg $=78,7$

5. Tingkat Kebisingan Mingguan per titik

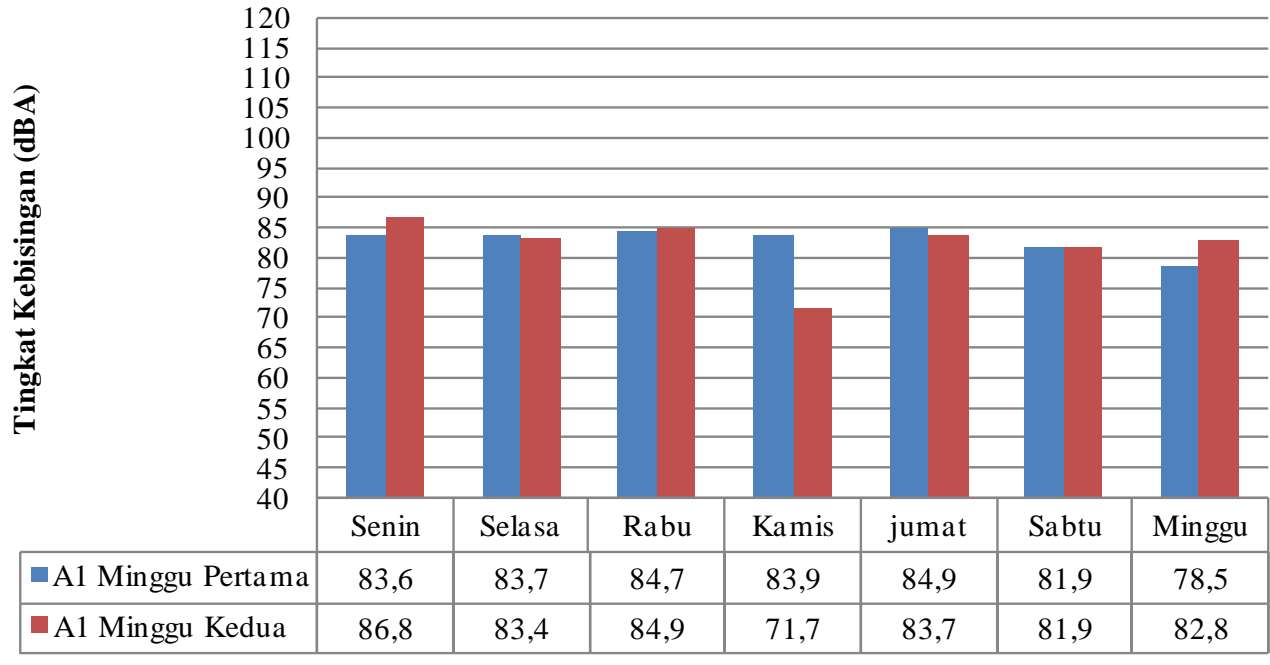

Gambar 3. Diagram Batang Leq titik pengamatan A1 


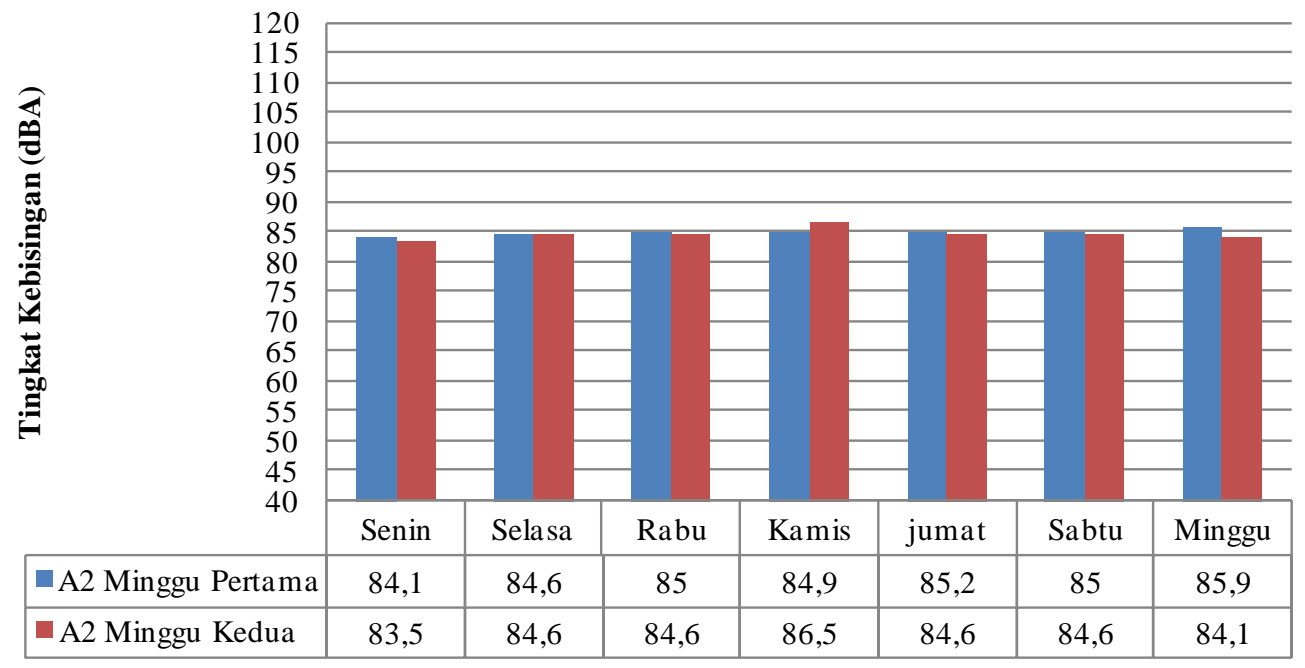

Gambar 4. Diagram Batang Leq titik pengamatan A2

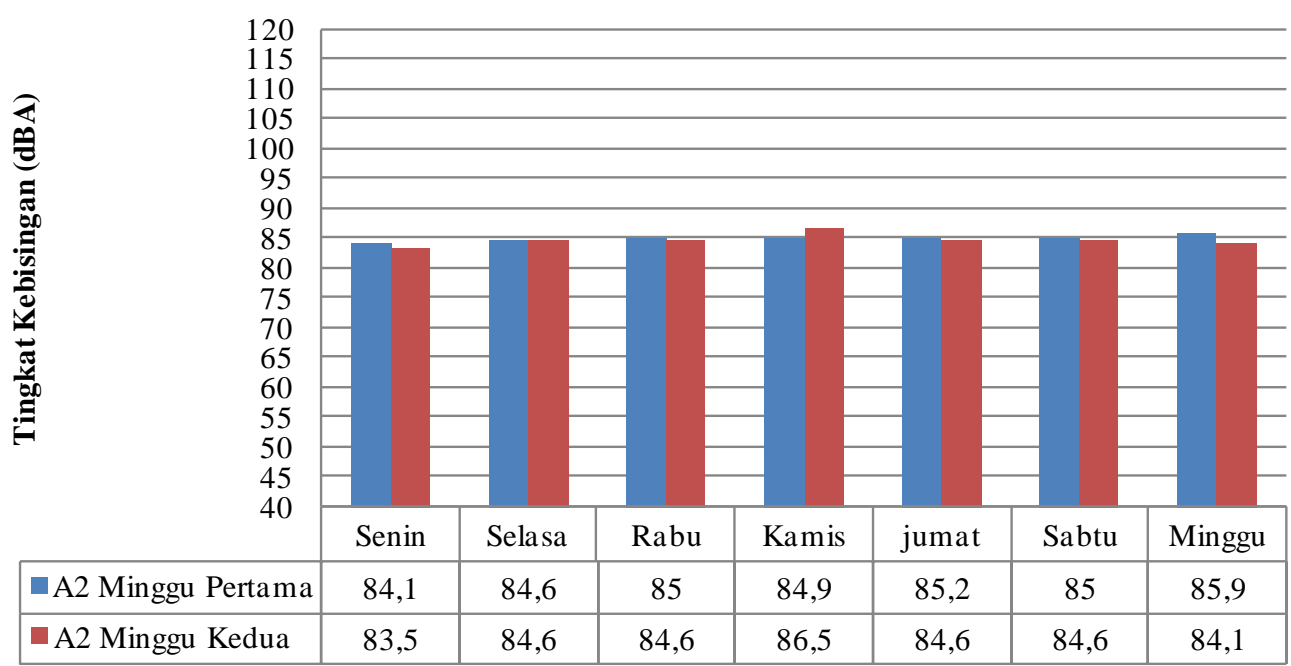

Gambar 5. Diagram Batang Leq titik pengamatan A3

\section{Analisis dan Pembahasan Penelitian Tingkat Kebisingan Areal Bandara DEO}

1. Tingkat Kebisingan Titik (A1) lokasi ujung Run Way bagian Barat

- Pada saat normal :

$\mathrm{L}_{\min }$ berkisar antara $50.8-58.6 \mathrm{dBA}, \mathrm{L}_{\max }$ berkisar antara $54.7-61.7 \mathrm{dBA}$, dan $\mathrm{L}_{\mathrm{eq}}$ berkisar antara $53.8-60.4 \mathrm{dBA}$.

- Pada saat landing

$\mathrm{L}_{\min }$ berkisar antara 51.0- 70.2 dBA, $\mathrm{L}_{\max }$ berkisar antara $56.5-77.2 \mathrm{~d} \mathrm{BA}$, dan $\mathrm{L}_{\mathrm{eq}}$ berkisar antara $57.0-74.9 \mathrm{dBA}$.

- Pada saat take off

$\mathrm{L}_{\text {min }}$ berkisar antara 52.6- 80.2 dBA, $\mathrm{L}_{\text {ma }}$ berkisar antara $54.0-79.7 \mathrm{dBA}$, dan $\mathrm{L}_{\mathrm{eq}}$ berkisar antara $57.0-75.8 \mathrm{dBA}$.

2. Tingkat Kebisingan Titik (A2) lokasi terminal penumpang

- Pada saat normal :

$\mathrm{L}_{\min }$ berkisar antara 51.2- $72.7 \mathrm{dBA}, \mathrm{L}_{\max }$ berkisar antara $56.7-71.7 \mathrm{dBA}$, dan $\mathrm{L}_{\mathrm{eq}}$ berkisar antara $55.5-70.2 \mathrm{dBA}$.

- Pada saat landing 
$\mathrm{L}_{\min }$ berkisar antara 53.1- $74.8 \mathrm{dBA}, \mathrm{L}_{\max }$ berkisar antara $59.5-79.5 \mathrm{dBA}$, dan $\mathrm{L}_{\text {eq }}$ berkisar antara $54.8-73.9 \mathrm{dBA}$.

- Pada saat take off

$\mathrm{L}_{\min }$ berkisar antara $52.6-72.2 \mathrm{dBA}, \mathrm{L}_{\max }$ berkisar antara $54.0-79.7 \mathrm{dBA}$, dan $\mathrm{L}_{\mathrm{eq}}$ berkisar antara $57.7-75.9 \mathrm{dBA}$

3. Tingkat Kebisingan Titik (A3) lokasi ujung Run Way bagian timur

- Pada saat normal :

$\mathrm{L}_{\min }$ berkisar antara 51.0 - 59.8 dBA, $\mathrm{L}_{\max }$ berkisar antara $53.9-65.3 \mathrm{dBA}$, dan $\mathrm{L}_{\mathrm{eq}}$ berkisar antara $53.8-60.4 \mathrm{dBA}$.

- Pada saat landing

$\mathrm{L}_{\min }$ berkisar antara 54.3- 80.7 dBA, $\mathrm{L}_{\max }$ berkisar antara $52.5-81.5 \mathrm{dBA}$, dan $\mathrm{L}_{\mathrm{eq}}$ berkisar antara $52.7-83.9 \mathrm{dBA}$.

- Pada saat take off

$\mathrm{L}_{\min }$ berkisar antara $50.8-80.2 \mathrm{dBA}, \mathrm{L}_{\max }$ berkisar antara $54.0-89.2 \mathrm{dBA}$, dan $\mathrm{L}_{\mathrm{eq}}$ berkisar antara $57.0-84.7 \mathrm{dBA}$.

\section{Pembahasan Hasil Pengukuran Kebisingan}

Tabel 3. Hasil Analisa

\begin{tabular}{|c|c|c|c|c|}
\hline $\begin{array}{c}\text { Lokasi } \\
\text { Pengukuran }\end{array}$ & \multicolumn{2}{|c|}{ Tingkat Kebisingan } & $\begin{array}{c}\text { Baku } \\
\text { Mutu }\end{array}$ \\
\hline & $\mathrm{L}_{\min }$ & $\mathrm{L}_{\max }$ & $\mathrm{L}_{\mathrm{eq}}$ & \\
Titik & dBA & dBA & dBA & dBA \\
\hline A1 & 70.2 & 79.7 & 75.8 & 55 \\
A2 & 74.8 & 77.5 & 75.9 & 60 \\
A3 & 80.7 & 89.2 & 84.7 & 55 \\
\hline
\end{tabular}

Ketrangan :

$\mathrm{L}_{\min } \quad$ : Tingkat Kebisingan Minimal pada saat pengukuran.

$\mathrm{L}_{\max } \quad$ : Tingkat Kebisingan Maksmal pada saat pengukuran

$\mathrm{L}_{\mathrm{eq}} \quad$ : Nilai Tingkat Kebisingan dari kebisingan yang berubah-ubah (fluktuatif) yang setara dengan tingkat kebisingan dari kebisingan yang tetap selama 10 menit

Berdasarkan hasil ketentuan sesuai dengan baku mutu tingkat kebisingan ketentuan Menteri Negara Lingkungan Hidup Nomor KEP.48/MENLH/11/1996, tanggal 25 Nopember 1996 tersebut di atas maka untuk daerah-daerah pemukiman seperti di Titik (A1) Ujung Landas Pacu Bagian Barat (75,8 dBA), dan A3 Ujung Landas Pacu Bagian Timur (84.7 dBA) di atas ambang baku mutu (55 dBA). Sesuai ketentuan Menteri Negara Lingkungan Hidup seperti lokasi Fasilitas Umum seperti Lokasi Terminal Bandara (75,9 dBA) dinyatakan di atas ambang baku mutu (60 dBA).

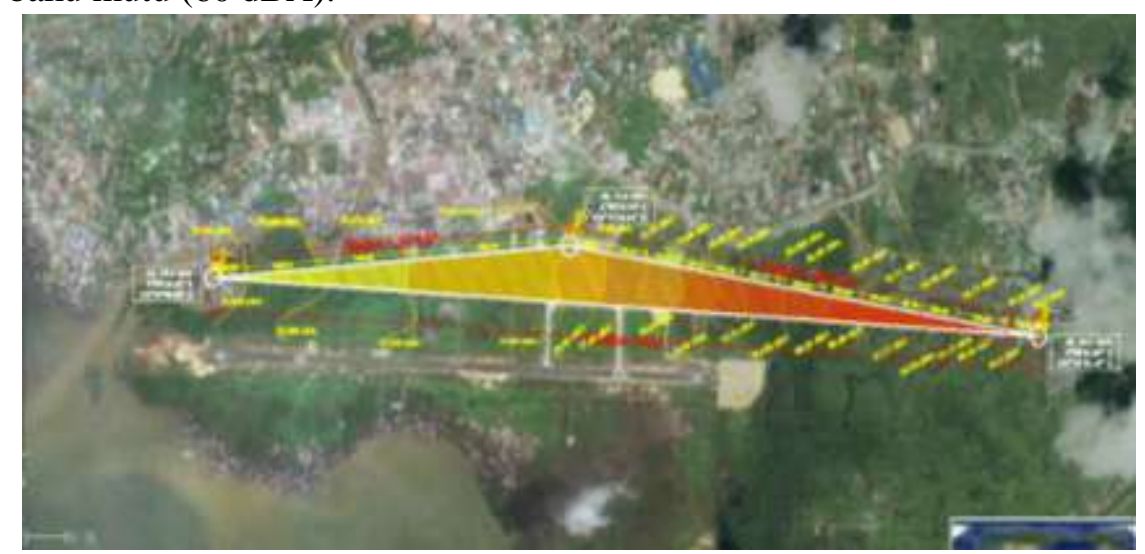

Gambar 6. Kontur nilai kebisingan daerah Bandara DEO Sorong 


\section{KESIMPULAN}

Simpulan dari penelitian ini adalah tingkat kebisingan di Bandara DEO Sorong terutama di lokasi pengukuran (A1) Sekitar landas pacu bagian barat (75,8dBA), dan (A3) Landas Pacu Bagian Timur (84,7 dBA) di atas ambang baku mutu (55 dBA). Dan (A2) Area terminal Penumpang (75,9 dBA) tingkat kebisingannya diatas ambang baku mutu ( $60 \mathrm{dBA}$ ).

\section{DAFTAR PUSTAKA}

1. _ 1996. KepMen LH No. 48/MNLH/11 Tentang baku kebisingan

$2 . \quad$ U Undang-undang Republik Indonesia Nomor 26 Tahun 2007, Penataan ruang.

3. Andi Riansayah, Mechanical catalog equipment and project specification K-3, Jakarta.1998. PT. Quadrant Utama, 1998, Noise Control Management. Bandung.

4. Basuki Heru, Merancang merencana lapangan terbang, Alumni 1985 Bandung.

5. Rangkuti Freddy, Analisis SWOT Teknik Membedah Kasus Bisnis, PT Gramedia Pustaka Utama Jakarta, 2006.

6. Sasongko D.P, Hadiyarto A, Sudharto P Hadi, Asmorohadi Nasio, Subagyo A, 2000, kebisingan Lingkungan, Badan Penerbit Universitas Diponegoro, Semarang.

7. Suma'mur, 2009. Higiene Perusahaan dan Kesehatan Kerja, Jakarta: Sagung Seto 